\title{
Product-service systems em laboratório de análises clínicas: um estudo de caso
}

\author{
Veridiana Rotondaro Pereira ${ }^{\mathrm{a}, \mathrm{b} *}$, Marly Monteiro de Carvalho ${ }^{\mathrm{b}}$, Roberto Gilioli Rotondaro ${ }^{\mathrm{b}}$ \\ ${ }^{a}$ Escola Superior de Engenharia e Gestão, São Paulo, SP, Brasil \\ bUniversidade de São Paulo, São Paulo, SP, Brasil \\ *rotondaro.veridiana@gmail.com
}

\begin{abstract}
Resumo
Cada vez mais as empresas oferecem soluções completas a seus clientes, com produtos e serviços. Essa mudança na composição do portfólio das organizações vem ocorrendo por uma série de razões, sejam relacionadas às questões estratégicas, motivadas por demandas do cliente, ou ainda por tendências que visam menores impactos ambientais. Este artigo visa contribuir com a literatura existente, adicionando a perspectiva do cliente neste cenário, por meio de um estudo de caso nos laboratórios de um dos principais hospitais da América Latina. Investigou-se a aquisição de equipamentos de análises clínicas, e os resultados mostram uma trajetória evolutiva de implementação do PSS durante as últimas décadas. Como cliente, este laboratório passou por três fases de evolução: primeiro como comprador de equipamentos, depois, numa segunda etapa, como os equipamentos não eram mais de propriedade do laboratório, passaram para contratos de leasing, e no terceiro estágio, para a aquisição de um contrato integrado de PSS, orientado a resultado. Nesta última fase, o laboratório observou vantagens importantes relacionadas tanto ao uso dos produtos quanto ao atendimento a demandas internas. Estas mudanças no processo de compra trouxeram importantes ganhos para o laboratório, como um sistema operacional seguro, a divisão dos riscos com o provedor da solução, suporte técnico especializado.
\end{abstract}

Palavras-chave

PSS. Servitização. Gestão de operação de serviço. Manufatura.

\section{Introdução}

Cada vez mais, as empresas oferecem soluções completas a seus clientes, com parcelas de produto e serviço, estabelecendo o que tem sido denominado na literatura como Sistema Produto-Serviço, do termo em inglês Product-Service System (PSS) (Goedkoop et al., 1999) ou Manufatura Orientada a Serviço, do termo em inglês Service-Oriented Manufacturing (SOM) (Fry et al., 1994). Essa mudança na composição do portfólio das organizações vem ocorrendo por uma série de motivos, sejam relacionados a questões estratégicas, motivados por demandas do cliente, ou ainda por tendências que visam menores impactos ambientais. Além de alterar a interação entre empresa e cliente, estabelecendo uma parceria colaborativa.

Muitos trabalhos (Johnson \& Mena, 2008; Lay et al., 2010; Slack et al., 2004) têm abordado os impactos que a adoção de um PSS traz para as empresas. Gebauer et al. (2010a) estudaram os padrões de mudanças de estratégia de serviços em empresas de manufatura, e os resultados mostraram alterações significativas na visão da empresa quanto à importância e estruturação dos serviços de pós-venda e seus impactos na relação empresa-cliente. Ainda sobre esse tema, mas com outro foco, Gebauer et al. (2010b) buscam entender se existe uma relação entre os diferentes elementos de orientação a serviços na cultura corporativa, em empresas de manufatura. Para Mathieu (2001), a oferta de uma solução completa implica importantes desafios para as empresas, como aumento de investimentos, mudanças no perfil de risco ou, ainda, a quebra do paradigma de que prover serviços esteja além de suas competências. A reestruturação acontece em vários níveis dentro 
da organização, onde novas métricas e incentivos tornam-se necessários. A ênfase do negócio passa de simples transação de venda de um produto para a oferta de uma solução completa (Neely, 2007a, b; Oliva \& Kallenberg, 2003), o que Baines et al. (2009) denominam estratégia de servitização centrada em produto.

Com o avanço da integração produto-serviço, o relacionamento fornecedor-cliente torna-se mais complexo e próximo. 0 cliente, que antes entrava em contato com o produto pronto, em alguns casos passa a participar de processos internos da empresa como projeto e planejamento. Segundo Goedkoop et al. (1999), Mont (2002) e Baines et al. (2007), os clientes demandam serviços e veem na integração produto-serviço vários aspectos positivos, como um aumento natural na diversidade de escolha no mercado, serviços de reparo e manutenção, novas formas de pagamento e, principalmente, novas propostas de uso do produto desenhado para atender às suas necessidades de modo pontual, além da possibilidade de não assumir a propriedade do bem. No entanto, pouco ainda tem sido estudado sobre as motivações que levam clientes a adquirirem soluções completas, bem como os impactos em suas estruturas de compras e suporte. Assim, percebe-se a existência de uma lacuna de estudos considerando a visão e necessidades dos clientes na aquisição de um PSS, identificando o impacto que a reestruturação das empresas têm na ótica do cliente.

Este trabalho visa contribuir para a literatura existente, acrescentando a perspectiva do laboratório de análises clínicas de um dos maiores hospitais públicos da América Latina e cliente de um Product-Service System (PSS) de equipamento diagnóstico. Como cliente, esse laboratório passou, nas últimas décadas, por uma trajetória evolutiva de aquisição de um PSS. 0 processo teve início na década de 1980, quando os equipamentos de diagnóstico eram comprados e tornavam-se ativos da instituição, onde não havia restrição de fornecedores na compra de insumos ou nos contratos de manutenção. Numa segunda fase, entre 1985 e o começo dos anos 1990, os equipamentos não eram mais de propriedade do laboratório que pagava apenas por sua locação, mantendo-se as mesmas regras para insumos e manutenção. A partir da metade da década de 1990, movido por demandas do governo e para evitar a obsolescência dos equipamentos, o referido laboratório passou a adquirir soluções completas integrando equipamentos, insumos, manutenção, assessoria técnica e suprimentos.

Este artigo está estruturado em cinco seções. A seção 2 apresenta uma visão sobre os conceitos de integração produto-serviço, abordados neste trabalho. A seção 3 apresenta os aspectos metodológicos aplicados na pesquisa, bem como uma descrição da empresa analisada no estudo. A seção 4 apresenta e discute os resultados da pesquisa. Finalmente, a seção 5 traz as conclusões.

\section{Integração produto-serviço: conceitos, características e evolução}

Muitos estudos têm focado o tema serviços, como Qualidade em Serviços (Pereira et al., 2013), porém, quando se trata de serviços na manufatura, é preciso olhar de forma questionadora para as definições. Lusch et al. (2007) argumentam que, desde a revolução industrial, ensina-se que a troca é sobre coisas, as quais podem ser trocadas por outras coisas. A manufatura foi considerada um processo com o objetivo de embutir valor tangível à matéria-prima. Assim, os serviços eram, na melhor das hipóteses, vistos como adicionais ao produto, ou ainda como fornecedores de valores especiais associados aos bens. Porém, para os estudiosos do tema, a troca não é sobre bens, pelo menos não de forma centralizada. Trata-se das partes aplicando suas competências especializadas em benefício da outra parte (ou seja, servi-los), e ao fazê-lo, beneficiando-se. Nesse sentido, o serviço é trocado por serviço (Vargo \& Lusch, 2004), e as mercadorias são mecanismos de distribuição para a prestação de serviços. Para Johnston \& Clark (2001), tanto as operações de serviços como as de manufatura compartilham a preocupação de transformar as entradas em saídas por meio de vários processos.

Mesmo não sendo o foco principal, as atividades de serviço representam um papel importante no desempenho de empresas de manufatura, ajudando a diferenciar o pacote de valor que a empresa oferece ao mercado, gerando um diferencial competitivo em relação aos concorrentes.

Para entender o papel de serviços na manufatura, é preciso mencionar o desenvolvimento dos critérios de competitividade da estratégia de manufatura. Segundo Spring \& Darlrymple (2000), em 1960 o foco era custo, qualidade e confiabilidade de entrega, passando na década de 1980 para flexibilidade e capacidade de inovação e, por fim, na década de 1990, o serviço surge com o status de um potencial ganhador de pedido.

Assim, inicialmente, o serviço surgiu na manufatura como uma forma de suportar e vender produtos. Tais produtos requeriam serviços ao longo de sua vida (aquisição, instalação, operação, melhorias, desativação, etc.) e possuíam um custo associado de propriedade, além do preço de compra (peças de reposição, consumíveis e manutenção, etc.). 
Gradativamente, as empresas têm oferecido soluções completas a seus clientes, envolvendo parcelas de produto e serviço. Essa mudança na composição do portfólio das organizações vem ocorrendo por uma série de motivos, sejam relacionados às questões estratégicas, motivados por demandas do cliente ou ainda por tendências que visam menores impactos ambientais.

Por se tratar de um tema multidisciplinar, é possivel encontrar na literatura mais de uma denominação para esse processo de transição, como Product-Service System (PSS), Industrial Product-Service System (APS) (Meier et al., 2011) ou ainda Service-Oriented Manufacturing (SOM).

O SOM é considerado um novo modo de produção através da integração da servitização com a indústria manufatureira tradicional (Fry et al., 1994; Zhen, 2012). Para Vandermerwe \& Rada (1988), adotando a estratégia SOM, as empresas manufatureiras tentam oferecer a seus clientes um pacote de produtos e serviços inovadores para atender suas necessidades específicas.

Visto um caso especial da servitização, o PSS é também conhecido como um modelo de negócio orientado à função (function-oriented business model) (Hesselbach \& Herrmann, 2011). O PSS surgiu em resposta a uma série de novas abordagens e tendências do mercado e vai além da simples agregação entre produtos e serviços, sendo frequentemente associado à mudança na estrutura de posse do bem. Neste artigo, o PSS também será mencionado como sistemas produto-serviço.

A literatura dispõe de várias abordagens e tendências que, em conjunto, levam ao desenvolvimento do PSS. Na visão de Mont (2002), entre outras, elas seriam: a venda do uso de produto em vez do produto em si, e a transição de uma sociedade de descarte para uma sociedade de recuperação. Cada uma dessas novas tendências requeria esforços que, quando empregados em separado, apresentavam uma série de limitações e restrições. Porém, quando atendidas em conjunto, compunham um sistema completo de solução para o cliente. Neste ponto, conhecer as diferenças entre serviços e produtos já não era mais relevante, uma vez que ambos são oferecidos como um sistema único e intrínseco. Segundo Mont (2002), esse conjunto busca facilitar a transição de sistemas de produção e consumo para um sistema único nos quais produtos, serviços, infraestrutura de apoio e redes são projetados para proporcionar uma determinada qualidade de vida aos consumidores e, ao mesmo tempo, têm o potencial de minimizar os impactos ambientais pela alteração dos padrões de consumo.
O PSS possui um grande número de definições. A primeira delas, proposta por Goedkoop et al. (1999), serviu como referência para os estudiosos do tema.

Apesar de apresentarem visões similares, conforme apontado por Mont (2002), ainda não existe um consenso sobre o termo. 0 presente estudo adotará o termo Product-Service System - PSS e a definição para esse conceito proposta por Wong (2004): 'PSS pode ser definido como uma solução oferecida para venda que envolve ambos, um produto e um elemento de serviço, para entregar a funcionalidade necessária'.

\subsection{Modelos de transição produto-serviço}

Conforme apontado por Baines et al. (2007), alguns autores (Environmental Life Cycle Information Management, 2005; Manzini \& Vezzoli, 2003; Manzini et al., 2001) apresentam diferentes classificações para o PSS ; no entanto, é possível destacar uma convergência entre ela, considerando-se o tipo de orientação: PSS orientado ao produto, PSS orientado ao uso e PSS orientado ao resultado. 0 PSS orientado ao produto vende o produto de forma tradicional, incluindo serviços adicionais, tais como o serviço pós-venda, manutenção e monitoramento para garantir a funcionalidade e durabilidade do produto, que é de propriedade do cliente (Aurich et al., 2010; Baines et al., 2007). O PSS orientado ao uso PSS envolve o uso ou disponibilidade de um produto que não é de propriedade do cliente, tais como o leasing e o compartilhamento (Aurich et al., 2010; Baines et al., 2007). Por último, o PSS orientado ao resultado envolve um resultado ou capacidade, em lugar de um produto, como o Rolls-Royce, que vende "power by the hour" em vez de motores (Baines et al., 2007), e a venda de roupas lavadas em vez de máquinas de lavar roupa (Fan \& Zhang, 2010).

Outros autores também tratam da transição da produção de bens de consumo para a provisão de serviço, porém com outras ênfases (Lusch et al., 2007; Oliva \& Kallenberg, 2003; Vandermerwe \& Rada, 1988; Vargo \& Lusch, 2004). Deste modo, é possivel fazer um paralelo entre eles e os diferentes conceitos de uso do produto que consideram o foco de desempenho do bem, mais do que sua propriedade em si. Para isso, serão utilizadas três diferentes proposições, o continuum de produto-serviço de Oliva \& Kallenberg (2003), a orientação de uso do produto no PSS (Baines et al., 2007) e as lógicas de transição de Vargo \& Lusch (2004). A Figura 1 sintetiza a concepção do processo de transição no contexto deste artigo.

Conforme a empresa avança nesse continuum, o produto deixa de ser o centro da proposta de 
valor para se tornar parte da oferta. Os serviços ganham importância dentro da organização, onde novas estruturas são formadas, com diretoria e equipe distintas em uma nova unidade de negócio. As empresas então passam a oferecer um portfólio mais amplo, composto por produtos, serviços e suas combinações na proporção requerida pelas necessidades dos clientes e disponibilidade de seus negócios. lsso pode ser visto como um processo de maturidade (Rapaccini et al., 2012).

\section{Métodos de pesquisa}

0 presente estudo adotou uma pesquisa exploratória de caráter qualitativo com objetivo de compreender as necessidades e fatores motivadores para aquisição de um Product-Service System (PSS), considerando a perspectiva do cliente. Assim, esta pesquisa foi realizada por meio de um levantamento do tipo estudo de caso, suportada por outros tipos de evidências como entrevistas presenciais, observação e análise documental.

\subsection{Critério para seleção do caso e instrumento de pesquisa}

Para atender ao objetivo descrito anteriormente, buscou-se identificar uma unidade de análise em que o cliente tivesse vivenciado todas as fases evolutivas do processo de transição, saindo da simples compra de bens, na qual os serviços são vistos como complemento, para a aquisição de um Product-Service System (PSS), seguindo orientações da literatura como Eisenhardt $\&$ Graebner (2007) e Voss et al. (2002).

0 instrumento de pesquisa foi elaborado com assertivas referentes aos Fatores Motivadores, na visão do cliente, para a aquisição de um Product-Service System (PSS), extraídas da literatura sobre o tema. 0 questionário final, a base teórica e os resultados obtidos na pesquisa encontram-se no Apêndice A.

\subsection{Unidade de análise}

A pesquisa de campo foi realizada no setor de laboratórios de análises clínicas de um hospital público brasileiro, que realiza exames de rotina hospitalar e ambulatorial, além de atender pacientes provenientes do serviço de convênios/particular. 0 laboratório funciona 24 horas por dia, ininterruptamente, a fim de atender solicitações de urgência. Executa aproximadamente 7,5 milhões de exames anualmente e conta com um menu de mais de 1.000 parâmetros (exames) diferentes. Na ocasião desta pesquisa, tinha um quadro funcional de 374 colaboradores e atende aproximadamente 2.500 pacientes ao dia.

Esta escolha atende aos requisitos estabelecidos anteriormente, uma vez que, como cliente, o laboratório passou por todas as fases evolutivas do processo de transição, descritas na Figura 1, saindo da simples compra de equipamentos de diagnóstico para a aquisição de um Product-Service System (PSS). Neste estudo, o laboratório será referido como LabA.

\subsection{Procedimento de coleta de dados}

As entrevistas presenciais foram realizadas com três funcionários do LabA: o diretor da instituição, o médico chefe responsável pelo serviço de Bioquímica Clínica e o técnico responsável por montar os processos de licitação de toda divisão de laboratórios. Os dois primeiros com mais de vinte anos na instituição, e o técnico atua há cinco anos na função. Além desses, outros sete funcionários foram entrevistados para aprofundamento nos processos do LabA. A Tabela 1 apresenta uma síntese do perfil dos entrevistados.

Os dados foram coletados por meio de entrevistas presenciais, com duração de 3 horas cada, as quais foram gravadas em meio digital e depois transcritas pelos autores deste artigo. Por questão de confidencialidade, as transcrições das entrevistas em sua íntegra não foram anexadas a este trabalho, mas as transcrições foram validadas pelos respondentes.

Lógica produto-dominante

Lógica serviço-dominante

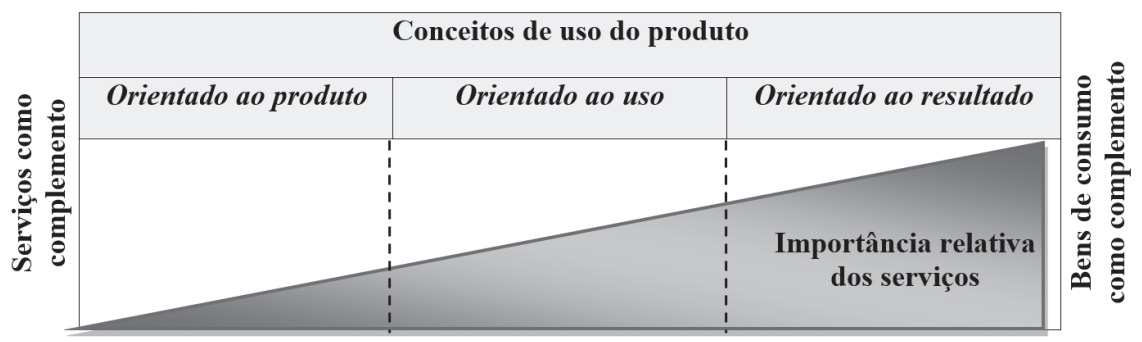

Figura 1. 0 continuum de produto-serviço versus os diferentes conceitos de uso do produto versus as lógicas de transição produto-serviço. Fonte: Adaptado de Baines et al. (2007), Oliva \& Kallenberg (2003) e Vargo \& Lusch (2004). 
As entrevistas foram conduzidas de forma aberta, isto é, os pesquisadores iniciavam explicando o tema de estudo e as informações que estavam buscando. Em seguida, o entrevistado passava a discorrer sobre o processo evolutivo de compra de equipamentos de diagnóstico. As entrevistas eram finalizadas com o questionário dos Fatores Motivadores para o cliente (Apêndice A). As entrevistas e visitas para coleta de dados ocorreram de janeiro de 2010 a junho de 2012.

Adicionalmente foram requisitados e analisados os documentos relativos ao processo de aquisição de equipamentos, tais como: "Contrato com Fornecedor", "Especificações de equipamentos e serviços" e "Rotinas de manutenção".

\section{Estudo de caso: análise do processo de evolução das modalidades de compra de equipamentos de análises clínicas}

Com base nas entrevistas, foi possível confirmar que o laboratório estudado não realizava mais a aquisição de equipamentos para análises clínicas e sim compra de sistemas produto-serviço (PSS), por eles denominada prestação de serviço.

A Figura 2 apresenta a evolução nas lógicas de transição vivenciada pelo LabA, partindo da compra de máquinas diagnósticas para a locação de equipamentos e, no estágio atual, para um contrato integrado de PSS, orientado a resultado, por exemplo, exames realizados. Esse processo é descrito pelo responsável do serviço de Bioquímica Clínica como uma evolução: "[...] nós fomos evoluindo por alternativas."

Para o diretor do LabA, esse processo está relacionado com a evolução dos laboratórios de forma geral. Para justificar essa perspectiva, o diretor traçou uma interessante perspectiva histórica, conforme explicado a seguir.

Quando os exames de análises clínicas começaram a ser realizados, os laboratórios eram desprovidos de qualquer processo que incluísse a questão tecnológica, e todos os exames eram feitos manualmente. Os laboratórios eram de pequeno porte e possuíam uma equipe de 3 a 5 pessoas.

Com o tempo, a população começou a ter acesso ao serviço de exames laboratoriais e consequentemente a demanda aumentou. Neste momento, surgiram empresas com interesse em suprir esse nicho de mercado. Com isso, nas décadas de 1960 e 1970 começaram a aparecer as primeiras empresas que produziam os chamados kits diagnósticos (conjunto de reagentes necessários para realizar determinado exame).

Esses kits, prontos para o uso, tornaram mais rápida e consistente a execução das análises, uma vez que os funcionários dos laboratórios não precisavam

Tabela 1. Perfil dos entrevistados do estudo de caso. Fonte: os autores.

\begin{tabular}{lccll}
\hline \multicolumn{1}{c}{ Cargo } & Sigla & Quant. & & Área \\
\hline Diretor do LabA & D & 1 & Patologia Clínica & \\
Médico chefe & M & 1 & Patologia Clínica & \\
Operacional Administrativo (Processos de Licitação) & OA & 1 & Patologia Clínica & \\
Operacional Técnico & OT & 7 & Patologia Clínica, enfermagem e administração \\
\hline
\end{tabular}

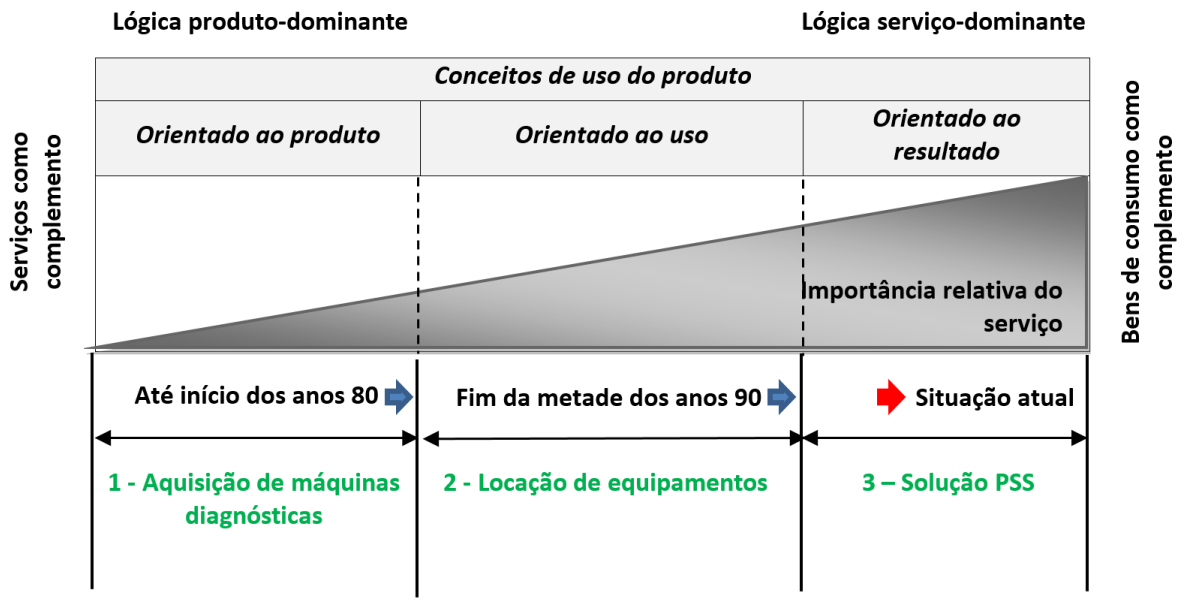

Figura 2. Evolução por alternativas: estudo de caso laboratório de análises clínicas. Fonte: os autores. 
mais combinar os reagentes, bastando abrir a caixa com o kit e realizar o procedimento. Mesmo assim, o processo ainda era bastante manual.

Como a demanda continuava a crescer e o mesmo acontecia com os laboratórios, a forma manual já não era adequada, pois a produtividade era baixa. Nesse momento, começaram a surgir, nos Estados Unidos, os primeiros equipamentos automatizados, que tentavam reproduzir as atividades repetitivas dos técnicos dentro do laboratório. No começo eram equipamentos muito caros, aos quais apenas poucos laboratórios no mundo tinham acesso, mas com o aumento da demanda houve também um incremento da produção e, consequentemente, os preços caíram, levando ao início da automação dos laboratórios.

Em paralelo a essa necessidade de aumento de produtividade, surgiram problemas relacionados à mão de obra, que começou a escassear. Em países do Primeiro Mundo não havia quantidade e nem qualidade suficiente de pessoas que pudessem suprir as necessidades de recursos humanos dos laboratórios. Então, a automação, além de aumentar a produtividade, contribuiu para amenizar a falta de mão de obra especializada. Assim, a introdução de equipamentos robotizados e depois informatizados foi uma necessidade para o laboratório.

No início da década de 1980, o LabA comprava os equipamentos de análises clínicas, que se tornavam sua propriedade (ativo). Como eram produzidos em baixa escala, esses equipamentos tinham preços elevadíssimos.
Uma das primeiras máquinas adquiridas pelo LabA custou em torno de 150 mil dólares, um valor alto segundo o diretor, mesmo levando em consideração que o serviço público (serviço beneficente) é isento do imposto de importação e do IPI.

A manutenção era contratada à parte por meio de um contrato de prestação de serviços, e os insumos (ex. conjuntos diagnósticos - kits) podiam ser adquiridos tanto do fornecedor do equipamento quanto de qualquer outra procedência (arquitetura aberta). Neste estudo, essa modalidade de compra será denominada ‘aquisição de máquinas diagnósticas', e suas principais características e Fatores Motivadores estão resumidos na Tabela 2, bem como o Evento de Transição para a próxima modalidade.

A grande limitação é que houve períodos em que a indústria queria apenas vender os equipamentos. Além dos fatores externos, ao longo do tempo foram surgindo fatores internos relativos tanto à organização quanto à dinâmica do trabalho que mudaram esse cenário de compra e as necessidades na perspectiva do LabA. Considerando que o LabA é um órgão público, todas as aquisições de bens de valor elevado, como no caso dos equipamentos, deveriam ser realizadas por meio de processos licitatórios, baseados na Lei no 8666/93, um processo demorado e complexo. Existia também a questão da sazonalidade da verba fornecida pelo Governo do Estado, além do estabelecimento de destinos específicos, ou seja, verbas de capital não poderiam ser utilizadas para serviços e vice-versa. Este fato levava a situações em que durante alguns

Tabela 2. Estudo de caso: detalhes da modalidade ‘aquisição de máquinas diagnósticas'. Fonte: os autores.

\section{1 - Aquisição de máquinas diagnósticas}

Características (C)

$\mathrm{C}_{1,1}$ - Equipamento de propriedade do laboratório.

$C_{1.2}$ - Equipamento com arquitetura aberta (pode ser abastecido com insumos de qualquer fornecedor).

$\mathrm{C}_{1.3}$ - Manutenção do equipamento contratada à parte.

$\mathrm{C}_{1.4}$ - $\mathrm{O}$ laboratório podia comprar os insumos (ex. conjuntos diagnósticos) de qualquer procedência (do fornecedor do equipamento ou de outro qualquer).

Fatores Motivadores para a transição (FM)

FM_C $_{1.1}$ - Sazonalidade da verba fornecida pelo Governo do Estado.

Situações:

$\Rightarrow 0$ laboratório tinha o equipamento, mas havia períodos de desabastecimento de insumos.

$\Rightarrow 0$ laboratório tinha os insumos e a máquina quebrava e não havia dinheiro para a manutenção.

$\Rightarrow 0$ laboratório tinha uma máquina boa, insumo disponível, mas o sistema de água tinha quebrado.

FM_C $C_{1.2}-$ Múltiplos fornecedores para contatar em caso de suporte técnico.

Múltiplos fornecedores:

- Equipamentos.

- Insumos como controles (kits diagnósticos).

- Sistema de purificação de água.

FM_C ${ }_{1.3}$ - Distribuição das verbas destinadas a aquisição de bens e serviços.

A verba que se destina à compra de bens materiais (ativos) vinha sendo congelada ao longo dos anos pelo Governo do Estado.

FM_C 1.4 - Múltiplos contatos dentro de um mesmo fornecedor.

- Setor de manutenção para questões referentes à manutenção dos equipamentos.

- Assessoria científica para questões referentes aos conjuntos diagnósticos.

- Vendas para questões referentes ao preço.

FM_C ${ }_{1.5}$ - Equipamentos muito caros, pois eram produzidos em baixa escala. 
períodos o laboratório tinha o equipamento, mas ficava desabastecido de insumos, e em outros, os insumos estavam disponíveis, mas a máquina quebrava e não havia verba para a manutenção. Poderia acontecer, ainda, de a máquina estar funcionando adequadamente, os insumos disponíveis, mas o sistema de tratamento de água que abastecia os equipamentos estar quebrado. Outro ponto importante era a distribuição das verbas destinadas à aquisição de bens materiais (ativos), que ao longo dos anos vinha sendo congelada pelo Governo do Estado.

0 LabA precisava tratar com múltiplos fornecedores de equipamentos, insumos (kits diagnósticos, etc.), sistema de purificação de água, entre outros. Também precisava manter múltiplos contatos dentro de um mesmo fornecedor: setor de manutenção para questões referentes à manutenção dos equipamentos, setor de assessoria científica para questões referentes aos conjuntos diagnósticos e setor de vendas para questões relativas à aquisição do equipamento.

Esses fatores, ao longo do tempo, tornaram o serviço de prestação de análises clínicas difícil de ser gerenciado, pois os processos internos tornavam-se mais complexos, demorados e, em alguns casos, inoperantes.

Em paralelo, a indústria de equipamentos de diagnóstico continuou a desenvolver novas máquinas, mas ainda a um preço muito alto, e poucos laboratórios no mundo conseguiam adquirir esses equipamentos. Até que a indústria mudou seu posicionamento e passou a oferecer uma solução conjunta para o cliente, pois ela produzia tanto os equipamentos quanto os insumos.

No início da década de 1980, o LabA teve permissão para fazer locação de equipamentos. Passou-se então para contratos de locação de equipamento em que o fornecedor disponibilizava a máquina diagnóstica (que permanecia de propriedade do fabricante) e a verba destinada à compra de ativo era utilizada para comprar insumos, sem restrição de fornecedor (arquitetura aberta). A manutenção era incluída no contrato de locação, que poderia conter outros componentes do processo de análises clínicas, como o sistema de purificação de água. Os contratos eram de cinco anos diretos, um requisito imposto pelo fornecedor selecionado como forma de amortizar os equipamentos por ele adquiridos. Ao final do contrato, o fornecedor retirava seus equipamentos das instalações do LabA, que não precisaria mais cuidar do descarte desse tipo de equipamento, muitas vezes complexo. A Tabela 3 apresenta as principais características e Fatores Motivadores da 'Locação de Equipamentos', bem como o Evento de Transição para a próxima modalidade.

Fatores motivadores, semelhantes à etapa anterior, como múltiplos fornecedores e contatos, além da sazonalidade da verba fornecida pelo Governo do

Tabela 3. Estudo de caso: detalhes da modalidade 'locação de equipamento'. Fonte: os autores.

\section{2 - Locaçãode equipamento}

Características (C)

$\mathrm{C}_{2,1}$ - Equipamento de propriedade do fornecedor.

$\mathrm{C}_{2.2}$ - Equipamento com arquitetura aberta (pode ser abastecido com insumos de qualquer fornecedor).

$\mathrm{C}_{2.3}^{2.2}$ - Locação do sistema de analisador bioquímico.

$\Rightarrow$ Os componentes do sistema de analisador bioquímico dependiam do tipo de contrato de negociado. Ex.: 0 laboratório fechava o contrato de locação para a máquina diagnóstica e adicionava outros itens, como o sistema de purificação de água.

$\mathrm{C}_{2,4}$ - A manutenção do equipamento fazia parte do contrato de locação.

$\mathrm{C}_{2.5}^{2.4}$ - $\mathrm{O}$ fornecedor fazia contratos de cinco anos diretos, como forma de amortizar os equipamentos.

$\mathrm{C}_{2.5} \mathrm{v} \mathrm{O}$ laboratório podia comprar os insumos (ex. conjuntos diagnósticos) de qualquer procedência (do fornecedor do equipamento ou de outro qualquer)

$\mathrm{C}_{2.7}$ - Alguns contratos contemplavam peças de reposição.

Fatores Motivadores para a transição (FM)

FM_C 2 - Evitar o sucateamento dos laboratórios.

FM_C ${ }_{2.1}$ - Múltiplos fornecedores para contatar em caso de suporte técnico.

Múltiplos fornecedores:

- Equipamentos + Sistema de purificação de água.

- Insumos como controles (kits diagnósticos).

Resolveu-se em parte a necessidade $\mathrm{FM}_{-} \mathrm{C}_{1,2}$.

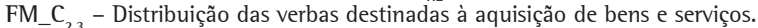

A verba que se destina à compra de bens materiais (ativos) vinha sendo congelada ao longo dos anos pelo Governo do Estado.

FM_C ${ }_{2.4}$ - Múltiplos contatos dentro de um mesmo fornecedor.

- Setor de manutenção para questões referentes à manutenção dos equipamentos.

- Assessoria científica para questões referentes aos conjuntos diagnósticos.

Vendas para questões referentes a preço.

Evento de transição: Esta alternativa foi permitida por um tempo pelo Governo do Estado e depois foi proibido fazer locações. 
Estado, motivaram a transição para a compra de Product-Service System (PSS), mas o ponto principal para o fim desta fase ocorreu quando o Governo do Estado proibiu as locações de equipamentos. Então, por volta do fim da metade dos anos 1990, passou-se para a compra de Product-Service System (PSS), denominada pelo LabA como 'prestação de serviços'. A Tabela 4 apresenta as principais características da modalidade 'Solução PSS', bem como suas principais vantagens.

A indústria continuou seu processo de evolução, levando algumas empresas do setor a se tornarem grandes corporações com um extenso portfólio de soluções. Um exemplo é o caso da Siemens, forte na área de imagem diagnóstica, e que, para aumentar seu portfólio de solução, comprou da Bayer a divisão de diagnósticos. Assim, eles passaram a oferecer para os hospitais e centros diagnósticos uma solução completa de imagem e análises clínicas, o que permitiu oferecer um preço final melhor. Além disso, lógicas de parceria de longo prazo começaram a ser delineadas.

Esse conceito se estendeu também aos hospitais e laboratórios que procuravam oferecer um portfólio completo de exames para o seu cliente.

A compra da solução completa, segundo explicação do responsável pelo serviço de Bioquímica Clínica, "[...] foi a saída para evitar o sucateamento dos laboratórios." lsso porque, com a compra de uma solução PSS, os laboratórios puderam renovar o parque de equipamentos, uma vez que o fornecedor disponibiliza máquinas de última geração como parte

Tabela 4. Estudo de caso: detalhes da modalidade 'solução PSS'. Fonte: os autores.

$$
3 \text { - Solução PSS }
$$

\section{Características (C)}

$\mathrm{C}_{3,1}$ - Equipamentos de propriedade do fornecedor ou, em alguns casos, terceirizados, mas tudo pelo fornecedor. Seja equipamento principal, analisadores e sistemas de suporte, bem como impressoras e purificadores de água.

$\mathrm{C}_{3.2}$ - A manutenção dos equipamentos faz parte do contrato de prestação de serviço e está contemplada no preço por determinação. lsto vale para todo o sistema disponibilizado: equipamento principal, analisadores e sistemas de suporte, bem como impressoras e purificadores de água.

$\mathrm{C}_{3.3}$ - $\mathrm{O}$ fornecedor disponibiliza os conjuntos diagnósticos (kits), a infraestrutura, os consumíveis (descartáveis que vão na máquina), os calibradores, as soluções de controle de qualidade e papelaria (papéis, cartuchos e tudo que for usado pelo sistema).

$\mathrm{C}_{3.4}$ - Preço por determinação (exame).

$\mathrm{C}_{3.5}$ - A logística de importar os equipamentos e insumos e todo o restante cabem ao fornecedor, que deverá se adequar para atender aos contratos.

$\mathrm{C}_{3.6}$ - Os contratos são anuais, podendo ser aditados por até cinco anos.

$\mathrm{C}_{3.7}$ - Definição de todo o serviço (determinações, métodos, tecnologias) feita pelo laboratório (cliente).

$\mathrm{C}_{3.8}^{3.7}$ - Os exames são realizados por técnicos do LabA.

$\mathrm{C}_{3.9}$-Equipamento com arquitetura fechada (só pode ser abastecido com insumos do próprio fabricante).

Especificações em contrato

- Quais exames serão realizados.

- Quantidade de exames prevista para ser executada.

- Descritivo da tecnologia e das metodologias a serem utilizadas, porque existem máquinas com diferentes tecnologias.

- Periodicidade de manutenção das máquinas.

- Mínimo de manutenção preventiva por ano.

- Descrição de como deve ser o fornecimento da água (sistema de purificação).

- Atualização de tecnologia durante a vigência do contrato, caso ocorra.

- Cláusulas referentes à legislação ambiental.

- Percentual de disponibilidade da máquina.

- SLA (Service LevelAgreement) Acordo de Nível de Serviço:

- Percentual de disponibilidade das máquinas.

MTBF (Mean Time Between Failures) - Tempo médio entre falhas e MTTR (Mean Time To Repair) - Tempo médio de reparo.

Vantagens listada em ordem de importância pelo cliente

Solução completa (serviço completo)

Contato único - SAC

- Independente do tipo de solicitação ou problema, o contato é feito com uma central de atendimento.

- 0 chamado gera um número de protocolo que pode ser monitorado pelo cliente via internet.

Atendimento personalizado.

- Gerente de produto - para as grandes contas.

- Equipe técnica especializada - Assessoria científica: técnicos (bioquímicos e biomédicos). Assessoria técnica: engenheiros. Relação de parceria fornecedor-cliente.

$\Rightarrow 0$ gerente de contas vai ao LabA verificar se existem novas licitações.

$\Rightarrow$ Participação em treinamentos internos do cliente e soluções de problemas não complexos.

Indicadores de desempenho definidos (pelo laboratório) em contrato para avaliação do serviço prestado. Estes indicadores definem se o contrato será ou não renovado após 1 ano. Exemplos: Tempo para atendimento de chamado; MTBF (Mean Time Between Failures) - Tempo Médio entre Falhas e MTTR (Mean Time To Repair) - Tempo Médio de Reparo; Eficácia da assessorial técnica. Pesquisas de Satisfação 
da solução e as substitui, sem custos, na ocorrência de melhoria técnica dos equipamentos.

Nessa modalidade, o LabA paga um preço por 'determinação' que na verdade é um exame. 0 fornecedor disponibiliza todo o sistema de análise diagnóstica, incluindo máquina, infraestrutura, consumíveis (descartáveis que vão ao equipamento), conjuntos diagnósticos (kits diagnósticos), calibradores e soluções de controle de qualidade. 0 sistema de purificação de água vem acoplado com todos os consumíveis e também sua manutenção. Sistemas de informática, papelaria (papéis, cartuchos, etc.), manutenção do sistema e assessoria técnica especializada (engenheiros, bioquímicos e biomédicos). 0 responsável pelo serviço de Bioquímica Clínica define o serviço como "[...] o fornecedor nos oferece uma prestação de serviços, entregando todos esses requisitos para que o LabA possa realizar determinado exame, e nós pagamos o pacote."

Para compor a solução completa, o fornecedor precisa buscar no mercado parceiros para os componentes que ele não produz. A composição dos parceiros varia de empresa para empresa, mas, como exemplo, podem ser citados fornecedores de sistemas de purificação de água, fornecedores de insumos, de sistemas de informática, entre outros. Essa parceria é denominada por Mont (2002) como redes de apoio. Porém, para o laboratório, o gerenciamento dessa rede de parceria não é visível, uma vez que o contato é único com o prestador, por meio de um gerente de produto.

Com a evolução dos equipamentos para manter a venda casada e a oferta de solução equipamento e insumos, as máquinas diagnósticas passaram para uma arquitetura fechada, isto é, só aceitavam insumos do próprio fabricante.

Como explicado anteriormente, sendo o LabA um órgão público, todas as contratações são feitas por meio de processos licitatórios (Brasil, 1993). Assim, o processo de compra por determinação é complexo e demorado, começando pelas áreas técnicas (Bioquímica Clínica, Biologia Molecular, Parasitologia, etc.), que fazem um descritivo de suas necessidades e a composição do mix de exames (quanto de cada exame será realizado no período contratado). Essas informações são passadas para o responsável por montar os processos licitatórios do laboratório. 0 responsável consolida as necessidades de cada área técnica e monta o processo licitatório de acordo com o que a lei determina, para depois encaminhar ao setor de administração e compras do hospital.

No momento do pregão (presenciais ou bolsa eletrônica de compra), as negociações são feitas sobre o preço da determinação de cada mix especificado. 0 médico chefe explica: “[...] Todas as regras do jogo estão descritas no contrato. A logística de importar equipamentos, insumos e todo o restante cabe ao fornecedor, que deverá se adequar para atender aos termos do contrato."

0 fornecedor ganhador do pregão elabora 0 contrato com informações detalhadas da prestação do serviço. Nele são descritos quais exames serão realizados, a quantidade de exames prevista para ser executada, o descritivo da tecnologia e das metodologias a serem utilizadas (existem máquinas com diferentes tecnologias para um mesmo tipo de determinação), a periodicidade de manutenção das máquinas, o mínimo de manutenção preventiva por ano, o nível de indicadores técnicos e do serviço, entre outras informações.

Inicialmente, os contratos de solução PSS eram de cinco anos, mas esse período foi proibido pelo Governo do Estado e, atualmente, os contratos são de um ano, podendo ser aditados por até cinco. A renovação dos contratos é controlada por indicadores definidos pelo laboratório e aceitos pelo fornecedor no momento do pregão. Se, no final do período de um ano, o fornecedor não estiver atendendo aos requisitos estipulados e medidos por meio dos indicadores, o contrato não é renovado. No contrato, também são previstas cláusulas relativas à legislação ambiental e atualização tecnológica dos equipamentos.

Vale ressaltar que, apesar de todo o suporte técnico prestado pelo fornecedor, é a equipe técnica composta por funcionários do laboratório que opera o sistema.

Devido ao tipo de serviço prestado, os fornecedores de equipamentos de diagnóstico são, em sua maioria, multinacionais e, devido às fusões ocorridas nos últimos cinco anos, o número de fornecedores passou de cinco grandes nomes para apenas dois.

As máquinas são dimensionadas para o mercado de países de Primeiro Mundo, como o americano e o europeu. No entanto, apesar de o mercado brasileiro tender a ter grandes laboratórios, nem sempre as soluções oferecidas são as melhores para a realidade nacional.

0 mercado brasileiro de equipamentos de diagnóstico apresenta características próprias e vem atraindo um interesse crescente dos fabricantes. Nos grandes mercados (americano e europeu), quem pode utilizar os serviços diagnósticos já o faz e não há expectativa de aumento de demanda no curto prazo. Nos países emergentes, como o Brasil, existe uma demanda reprimida que começa a ter acesso a esse tipo de serviço, então as possibilidades de ganho de escala são grandes.

Para o laboratório, um Product-Service System (PSS) que atenda às suas necessidades precisa oferecer um sistema operante com qualidade com máquinas 
e insumos de boa qualidade, sistema de purificação de água de primeira linha, manutenção corretiva e preventiva que atenda aos requisitos especificados e assessoria técnica especializada e treinada (engenheiros, bioquímicos e biomédicos).

Já os fornecedores de um Product-Service System (PSS) devem atender a critérios fundamentais como honestidade no cumprimento das especificações de contrato, oferecer soluções com a qualidade prometida, cumprimento de prazos para atendimento - SLA (Service Level Agreement), canal direto de comunicação, equipe técnica qualificada e preço adequado.

Como principal desvantagem dessa modalidade, o LabA cita o alto grau de complexidade do processo de elaboração do descritivo da licitação, além de ser muito demorado e demandar recursos dedicados. São meses de descrição, sendo preciso descrever detalhe por detalhe.

\subsection{Fatores motivadores}

A seguir, é apresentado um resumo das notas e comentários sobre os fatores motivadores para a oferta de sistemas produto-serviço (PSS) na perspectiva do cliente, baseados na literatura pesquisada, conforme Tabela apresentada no Apêndice A.

Para avaliar os fatores motivadores, foram utilizadas as questões fechadas disponiveis no Apêndice A, que também apresenta o grau de concordância para os fatores motivadores na visão dos entrevistados.

A seguir serão apresentados os comentários específicos para alguns dos fatores motivadores.

$\mathrm{FMC}_{1}$ - As empresas de solução produto-serviço têm maior foco nas questões relacionadas às dimensões ambientais do que as empresas tradicionais.

Para o LabA, as questões relativas à gestão ambiental não são apenas fatores motivadores, mas uma exigência da sociedade.

Para os fornecedores, trabalhar numa situação em que é preciso produzir menos quantidade de resíduos de forma a gerar menores impactos ambientais reverte em custos, sendo desse modo necessário rever uma série de conceitos até mesmo dentro do equipamento.

A empresa só se motiva porque isso é uma exigência dos consumidores, que entendem que o fornecedor deve dar um destino aos resíduos (sejam eles contaminantes ou não), ou ainda produzir máquinas que produzem menos resíduos. 0 LabA exige em contrato que o fornecedor cumpra com as normas ambientais, porém, nesse caso, o próprio laboratório é responsável por dar destino aos resíduos dos equipamentos. Existe uma empresa contratada somente para esta finalidade.
FMC2 - As empresas de solução produto-serviço têm maior potencial de satisfação das preferências dos consumidores do que as empresas tradicionais.

Sim, isto é competitividade. 0 diretor afirma: “[...] o laboratório vive de inovações. Se a empresa não fizer uma solução que atende às necessidades $\mathrm{e}$ inove, está fora do mercado.”

FMC6 - Nas soluções produto-serviço, os serviços venda são especializados e auxiliam a tomada de decisão.

As empresas têm os gerentes de produto dedicados às grandes contas, como é o caso do LabA. Segundo o diretor, "[...] Eles são especialistas nisto." A médica chefe explicou que os gerentes de conta dedicados ao LabA passam parte de seu tempo dentro do laboratório buscando informações sobre novas licitações.

FMC8 - Nas soluções produto-serviço, a propriedade do bem não se encontra mais com o cliente, que passa a pagar apenas pelo seu uso, adquirindo benefícios como a reestruturação dos riscos, responsabilidades e custos normalmente associados à compra do produto.

Se ocorrerem problemas com a prestação do serviço, como erro de análise clínica que afete um cliente do laboratório, imediatamente é acionado um grupo de análise de falhas composto por funcionários, tanto do laboratório quanto do fornecedor, para determinar a causa da falha e assim definir responsabilidades.

No entanto, em última instância, a responsabilidade para com o cliente final é do laboratório.

FMC10 - Nas soluções produto-serviço, o cliente passa a ser cocriador de valor.

Quando o fabricante lança uma nova tecnologia, os clientes recebem treinamento para utilizá-la e, em alguns casos, os especialistas responsáveis pelos desenvolvimentos vêm ao Brasil conversar com os técnicos do cliente que utilizam os equipamentos e discutir necessidades e adequações. Dessa interação surgem novas ideias e melhorias.

FMC11 - Nas soluções produto-serviço, o cliente torna-se coprodutor, o que incentiva a troca de informações.

Os fornecedores são muito colaborativos neste sentido, pois têm interesse na troca de informação.

FMC16 - Nas soluções produto-serviço, a probabilidade de se estabelecer a coprodução é maior quando uma das partes possui as ferramentas necessárias, espaço ou ambos. 
No caso do LabA, os fornecedores de máquinas diagnósticas oferecem assessoria científica, treinamento para novas técnicas e serviço 24 horas. Segundo explicado pelo médico chefe, eles têm interesse em valorizar aquilo que produzem e implantam, como um novo tipo de exame. Segundo o diretor, “[...] vem muita coisa agregada, sim. Não basta ter um bom produto, é preciso dar outros tipos de conhecimento para, assim, agregar valor." É o estabelecimento de uma relação de parceria.

\section{Conclusões}

Para atingir o objetivo de contribuir para a literatura existente, acrescentando a perspectiva do laboratório de análises clínicas de um dos maiores hospitais públicos da América Latina, e cliente de um Product-Service System (PSS) de equipamento diagnóstico, conduziu-se uma pesquisa qualitativa por meio de estudo de caso, realizada nos laboratórios de um hospital público da cidade de São Paulo.

De acordo com as informações coletadas, o cliente laboratório público, LabA, começou o processo de transição de compra de equipamentos de diagnóstico para a aquisição de sistemas produto-serviço no início dos anos 1980 e, ao longo dos anos, foi evoluindo por alternativas. Atualmente, os contratos são fechados por mix de exames e os preços fixados por determinação (exames), modalidade por eles denominada como prestação de serviço.

Muitos fatores levaram o laboratório a adotar um Product-Service System (PSS), como atendimento a diretrizes do próprio setor, por se tratar de um órgão público ou para suprir a escassez de mão de obra especializada, ou ainda devido ao reposicionamento dos fabricantes dos equipamentos, que passaram a oferecer máquinas com arquitetura fechada.

0 processo evolutivo passou pelas fases discutidas na Figura 2, e algumas questões identificadas na literatura merecem destaque com relação a suas aplicações no contexto da pesquisa, como o estabelecimento de redes de apoio, uma vez que, para compor a solução completa, o fornecedor precisa buscar no mercado parceiros para os componentes que ele não produz.

No entanto, apesar de a literatura consultada considerar soluções personalizadas para a venda produto-serviço, no caso de equipamentos de diagnóstico não há solução personalizada para o mercado brasileiro, já que os equipamentos são dimensionados para o mercado de países de Primeiro Mundo, como o americano e o europeu.

A coprodução é estabelecida de forma clara neste contexto, uma vez que, apesar de todo o suporte técnico prestado pelo fornecedor, é a equipe técnica composta por funcionários do laboratório que opera o sistema.

Já as questões ambientais são vistas pelo LabA não como um fator motivador para a oferta de soluções produto-serviço, mas sim como uma exigência da sociedade. Para a empresa, trabalhar numa situação em que é preciso produzir menos resíduos de forma a gerar menores impactos ambientais acaba revertendo em custos para a solução e para o projeto, sendo necessário rever uma série de conceitos até mesmo dentro do equipamento. A empresa só se motiva porque isso é uma exigência dos consumidores, que entendem que o fornecedor deve dar um destino aos resíduos (sejam eles contaminantes ou não), ou ainda, criar máquinas que produzam menos resíduos. Assim, a questão ambiental não é um fator motivador, mas sim uma exigência.

Outro ponto importante identificado diz respeito aos equipamentos com arquitetura fechada, em que o cliente é obrigado a comprar insumos do fabricante do equipamento ou da solução. Desse modo, o cliente opta pela compra de um Product-Service System (PSS), não só pelas diversas vantagens citadas anteriormente, mas também porque o desenho da solução o obriga.

Por se tratar de uma análise qualitativa baseada em um estudo de caso único realizado no laboratório de análises clínicas de um dos maiores hospitais públicos da América Latina, os dados coletados não permitem que as conclusões sejam generalizadas. Assim, sugere-se que este estudo seja replicado em outros setores, considerando a visão de outros clientes na adoção de um Product-Service System (PSS).

\section{Referências}

Aurich, J. C., Mannweiler, C., \& Schweitzer, E. (2010). How to design and offer services successfully. Journal of Manufacturing Science and Technology, 2(3), 136-143. http://dx.doi.org/10.1016/j.cirpj.2010.03.002.

Baines, T. S., Lightfoot, H. W., Evans, S., Neely, A., Greenough, R., Peppard, J., Roy, R., Shehab, E., Braganza, A., Tiwari, A., Alcock, J. R., Angus, J. P., Bastl, M., Cousens, A., lrving, P., Johnson, M., Kingston, J., Lockett, H., Martinez, V., Michele, P., Tranfield, D., Walton, I. M., \& Wilson, H. (2007). State-of-the-art in product-service systems. Proceedings of the Institution of Mechanical Engineers. Part B, Journal of Engineering Manufacture, 221(10), 1543-1552. http:// dx.doi.org/10.1243/09544054JEM858.

Baines, T. S., Lightfoot, H. W., Peppard, J., Johnson, M., Tiwari, A., Shehab, E., \& Swink, M. (2009). Towards an operations strategy for product-centric servitization. International Journal of Operations \& Production Management, 29(5), 494-519. http://dx.doi.org/10.1108/01443570910953603.

Bowen, J. \& Ford, R. C. (2002). Managing service organizations: does having a "thing" make a difference? Journal of Management, 28(3), 447-469. http://dx.doi.org/10.1016/ S0149-2063(02)00135-6 
Brasil. (1993, Junho 22). Regulamenta o art. 37, inciso XXI, da Constituição Federal, institui normas para licitações e contratos da Administração Pública e dá outras providências (Lei $n^{\circ}$ 8.666, 21 de junho de 1993). Diário Oficial da União. Recuperado em 01 de dezembro de 2014, de http://www. planalto.gov.br/ccivil_03/Leis/L8666cons.htm

Eisenhardt, K. M., \& Graebner, M. E. (2007). Theory building from cases: opportunities and challenges. Academy of Management Journal, 50(1), 25-32. http://dx.doi. org/10.5465/AMJ.2007.24160888.

Environmental Life Cycle Information Management - ELIMA. (2005). Product life cycle technology - results and implications for business strategy. In Elima Seminar, Vienna, Austria.

Fan, X., \& Zhang, H. (2010). Aligning product-service systems with market forces: a theoretical framework. In Proceedings of the 2010 International Conference on Service SciencesICSS, China.. http://dx.doi.org/10.1109/1CSS.2010.59.

Fry, T. D., Steele, D. C., \& Saladin, B. A. (1994). A Serviceoriented manufacturing strategy. International Journal of Operations \& Production Management, 14(10), 17-29. http://dx.doi.org/10.1108/01443579410067225.

Gebauer, H., Edvardsson, B., \& Bjurko, M. (2010a). The impact of service orientation in corporate culture on business performance in manufacturing companies. Journal of Service Management, 21(2), 237-259. http://dx.doi. org/10.1108/09564231011039303.

Gebauer, H., Fischer, T., \& Fleisch, E. (2010b). Exploring the interrelationship among patterns of service strategy changes and organizational design elements. Journal of Service Management, 21(1), 103-129. http://dx.doi. org/10.1108/09564231011025137.

Goedkoop, M., van Haler, C., Riele, H. \& Rommers, P. (1999). Product service-systems, ecological and economic basics. Netherlands: PricewaterhouseCoopers/ Storrm C.S / PRé consultants.

Hesselbach, J., \& Herrmann, C. (2011). Functional thinking for value creation. 3rd International Conference on ProductService Systems, Germany.. http://dx.doi.org/10.1007/9783-642-19689-8.

Johnson, M., \& Mena, C. (2008). Supply chain management for servitised products: a multi-industry case study. International Journal of Production Economics, 114(1), 27-39. http:// dx.doi.org/10.1016/j.jpe.2007.09.011.

Johnston, R., \& Clark, G. (2001). Service operations management. Harlow: Prentice-Hall.

Lay, G., Copani, G., Jäger, A., \& Biege, S. (2010). The relevance of service in European manufacturing industries. Journal of Service Management, 21(5), 715-726. http://dx.doi. org/10.1108/09564231011092908.

Lusch, R. F., Vargo, S. L., \& O’Brien, M. (2007). Competing through service: Insights from service-dominant logic. Journal of Retailing, 83(1), 5-18. http://dx.doi.org/10.1016/j. jretai.2006.10.002.

Manzini, E., \& Vezzoli, C. (2003). A strategic design approach to develop sustainable product service systems: examples taken from the 'environmentally friendly innovation' Italian prize. Journal of Cleaner Production, 11(8), 851-857. http:// dx.doi.org/10.1016/S0959-6526(02)00153-1.

Manzini, E., Vezzoli, C., \& Clark, G. (2001). Product-service systems: using an existing concept as a new approach sustainability. Journal of Desert Research, 1(2)
Mathieu, V. (2001). Services strategies within the manufacturing sector: benefits, costs and patnership. International Journal of Service Industry Management, 12(5), 451-475. http:// dx.doi.org/10.1108/EUM0000000006093.

Meier, H., Völker, O., \& Funke, B. (2011). Industrial ProductService Systems (IPS2). International Journal of Advanced Manufacturing Technology, 52(9-12), 1175-1191. http:// dx.doi.org/10.1007/s00170-010-2764-6.

Meijkamp, R. (2000). Changing consumer behaviour through eco-efficient services: an empirical study of car sharing in The Netherlands. Delft: Delft University of Technology.

Mont, O. K. (2002). Clarifying the concept of product-service system. Journal of Cleaner Production, 10(3), 237-245. http://dx.doi.org/10.1016/S0959-6526(01)00039-7.

Neely, A. (2007a). The servitization of manufacturing: an analysis of global trends. In POMS College Of Service Operations, London.

Neely, A. (2007b). The servitization of manufacturing: an analysis of global trends. In 14th European Operations Management Association Conference, Ankara.

Oliva, R., \& Kallenberg, R. (2003). Managing the transition from products to services. International Journal of Service Industry Management, 14(2), 160-172. http://dx.doi. org/10.1108/09564230310474138.

Pereira, V. R., Carvalho, M. M., \& Rotondaro, R. G. (2013). Um estudo bibliométrico sobre a evolução da pesquisa da qualidade em serviço. Produção, 23(2), 312-328. http:// dx.doi.org/10.1590/S0103-65132012005000053. [Epub em: 02 de agosto de 2012]

Rapaccini, M., Saccani, N., Pezzotta, G., Burger, T., \& Ganz, W. (2012). Service development in product-service systems: a maturity model. Service Industries Journal, 33(3-4), 300319. http://dx.doi.org/10.1080/02642069.2013.747513.

Slack, N., Lewis, M., \& Bates, H. (2004). The two worlds of operations management research and practice - Can they meet, should they meet? International Journal of Operations \& Production Management, 24(3-4), 372-387. http:// dx.doi.org/10.1108/01443570410524640.

Spring, M., \& Dalrymple, J. F. (2000). Product customisation and manufacturing strategy. International Journal of Operations \& Production Management, 20(3-4), 441-467. http://dx.doi.org/10.1108/01443570010314782.

Vandermerwe, S., \& Rada, J. (1988). Servitization of business: adding value by adding services. European Management Journal, 6(4), 314-324. http://dx.doi.org/10.1016/02632373(88)90033-3.

Vargo, S. L., \& Lusch, R. F. (2004). Evolving to a new dominant logic for marketing. Journal of Marketing, 68(1), 1-17. http://dx.doi.org/10.1509/jmkg.68.1.1.24036.

Voss, C., Tsikriktsis, N., \& Frohlich, M. (2002). Case research in operations management. International Journal of Operations \& Production Management, 22(2), 195-219. http://dx.doi. org/10.1108/01443570210414329.

Wong, M. (2004). PSS in the consumer goods industry (Tese de doutorado). Cambridge University, Cambridge.

Zhen, L. (2012). An analytical study on service-oriented manufacturing strategies. International Journal of Production Economics, 139(1), 220-228. http://dx.doi.org/10.1016/j. ijpe.2012.04.010. 


\title{
Product-service systems in a clinical laboratory: a case study
}

\begin{abstract}
Increasingly, companies offer complete solutions, which include products and services, to its customers. This change in organizations' portfolios has been occurring for a number of reasons: strategic issues, customer demands, or even low environmental impact trends. This paper aims to add the customer's perspective on such a scenario through a case study in the laboratories of one of the major Latin American public hospitals. The acquisition of clinical analysis equipment was investigated; the results show an evolutionary trajectory of PSS implementation during the last decades. As a customer, this laboratory went through three phases of evolution: first, as equipment buyer; second, when equipment was no longer laboratory property, changing to leasing contracts; and third, a new method of purchasing, called the PSS solution. In this third phase, the laboratory observed important advantages related to product use and internal demands. The changes in the purchase process brought important gains to the laboratory, such as a secure operating system, risks shared with the solution provider, and specialized technical support.
\end{abstract}

Keywords

PSS. Servitization. Operations service management. Manufacturing. 
Apêndice A. Fatores motivadores para o PSS na perspectiva do cliente

A escala de 1 a 5 indica o grau de concordância do entrevistado, conforme a seguir: "1" para "Discordo Totalmente", "2" para "Discordo", “3" para "Não concordo nem discordo", “4” para "Concordo" e "5" para "Concordo Totalmente". As siglas utilizadas nesta tabela são D para o Diretor do Laboratório e M para o Médico Chefe.

\begin{tabular}{|c|c|c|c|c|c|c|}
\hline Fator Motivador & Base Teórica & 1 & 2 & 3 & 4 & 5 \\
\hline $\begin{array}{l}\mathrm{FMC}_{1} \text { - As empresas de solução produto-serviço têm maior foco nas questões } \\
\text { relacionadas às dimensões ambientais do que as empresas tradicionais. }\end{array}$ & \multirow{2}{*}{ (Mont, 2002) } & & & $\begin{array}{l}\mathrm{D} \\
\mathrm{M}\end{array}$ & & \\
\hline $\begin{array}{l}\mathrm{FMC}_{2} \text { - As empresas de solução produto-serviço têm maior potencial de } \\
\text { satisfação das preferências dos consumidores do que as empresas tradicionais. }\end{array}$ & & & & & $\begin{array}{l}\mathrm{D} \\
\mathrm{M}\end{array}$ & \\
\hline $\begin{array}{l}\mathrm{FMC}_{3} \text { - Nas soluções produto-serviço, as combinações entre produtos e serviços } \\
\text { aumentam a gama de ofertas de forma a atender necessidades específicas. }\end{array}$ & \multirow{3}{*}{$\begin{array}{l}\text { (Baines et al., 2007; } \\
\text { Goedkoop et al., 1999; Mont, } \\
\text { 2002) }\end{array}$} & & & M & $\mathrm{D}$ & \\
\hline $\begin{array}{l}\mathrm{FMC}_{4}-\mathrm{A} \text { oferta de soluções integrando produto-serviço permite a flexibilização } \\
\text { dos modos de pagamento, tais como pagamento por utilização, por produto, por } \\
\text { aluguel, por leasing, entre outros. }\end{array}$ & & & & & $\mathrm{D}$ & M \\
\hline $\begin{array}{l}\mathrm{FMC}_{5} \text { - A oferta de soluções integrando produto-serviço possibilita novas } \\
\text { propostas de uso do produto e/ou serviço, desenhados para atender necessidades } \\
\text { específicas dos clientes. }\end{array}$ & & & & & $\begin{array}{l}\mathrm{D} \\
\mathrm{M}\end{array}$ & \\
\hline $\begin{array}{l}\text { FMC }_{6}-\text { Nas soluções produto-serviço, os serviços venda são especializados e } \\
\text { auxiliam a tomada de decisão. }\end{array}$ & (Oliva \& Kallenberg, 2003) & & & & $\mathrm{D}$ & M \\
\hline $\begin{array}{l}\mathrm{FMC}_{7} \vee \mathrm{A} \text { oferta de soluções integrando produto-serviço possibilita a compra do } \\
\text { produto quando e onde quiser. }\end{array}$ & (Mont, 2002) & & & & $\begin{array}{l}\mathrm{D} \\
\mathrm{M}\end{array}$ & \\
\hline $\begin{array}{l}\mathrm{FMC}_{8} \vee \text { Nas soluções produto-serviço, a propriedade do bem não se encontra } \\
\text { mais com o cliente, que passa a pagar apenas pelo seu uso, adquirindo benefícios } \\
\text { como a reestruturação dos riscos, responsabilidades e custos normalmente } \\
\text { associados à compra do produto. }\end{array}$ & $\begin{array}{l}\text { (Baines et al., 2007; } \\
\text { Goedkoop et al., 1999; Mont, } \\
\text { 2002) }\end{array}$ & & & & $\begin{array}{l}\mathrm{D} \\
\mathrm{M}\end{array}$ & \\
\hline $\begin{array}{l}\mathrm{FMC}_{9}-\text { Nas soluções produto-serviço, a precificação é estudada caso a caso, para } \\
\text { o pacote único oferecido ao cliente. }\end{array}$ & (Lusch et al., 2007) & & & & $\begin{array}{l}\mathrm{D} \\
\mathrm{M}\end{array}$ & \\
\hline $\mathrm{FMC}_{10}-$ Nas soluções produto-serviço, o cliente passa a ser cocriador de valor. & $\begin{array}{l}\text { (Bowen \& Ford, 2002; Vargo } \\
\text { \& Lusch, 2004) }\end{array}$ & & & & $\begin{array}{l}\mathrm{D} \\
\mathrm{M}\end{array}$ & \\
\hline $\begin{array}{l}\mathrm{FMC}_{11} \text { - Nas soluções produto-serviço, o cliente torna-se coprodutor, o que } \\
\text { incentiva a troca de informações. }\end{array}$ & \multirow{6}{*}{ (Lusch et al., 2007) } & & & & $\begin{array}{l}\mathrm{D} \\
\mathrm{M}\end{array}$ & \\
\hline $\begin{array}{l}\mathrm{FMC}_{12}-\text { Nas soluções produto-serviço, o cliente torna-se coprodutor e passa a } \\
\text { participar de soluções personalizadas. }\end{array}$ & & & $\mathrm{D}$ & M & & \\
\hline $\begin{array}{l}\mathrm{FMC}_{13} \text { - Nas soluções produto-serviço, o cliente determina o grau de } \\
\text { envolvimento desejado na coprodução do serviço. }\end{array}$ & & & & & $\mathrm{D}$ & \\
\hline $\begin{array}{l}\mathrm{FMC}_{14}-\text { Nas soluções produto-serviço, quando um cliente tem conhecimento } \\
\text { sobre determinado tema, ele se torna mais propenso a participar como coprodutor } \\
\text { de um determinado serviço. }\end{array}$ & & & & $\mathrm{D}$ & & \\
\hline $\begin{array}{l}\mathrm{FMC}_{15}-\text { Nas soluções produto-serviço, existe uma tendência natural à } \\
\text { coprodução quando o cliente deseja um maior controle sobre o processo ou } \\
\text { resultado do serviço. }\end{array}$ & & & & & $\mathrm{D}$ & M \\
\hline $\begin{array}{l}\mathrm{FMC}_{16} \text { - Nas soluções produto-serviço, a probabilidade de se estabelecer a } \\
\text { coprodução é maior quando uma das partes possui as ferramentas necessárias, } \\
\text { espaço ou ambos. }\end{array}$ & & & & $\begin{array}{l}\mathrm{D} \\
\mathrm{M}\end{array}$ & & \\
\hline $\begin{array}{l}\mathrm{FMC}_{17}-\text { Nas soluções produto-serviço, a coprodução permite a oferta de } \\
\text { serviços sem custo trazendo, assim, a percepção de benefícios econômicos ao } \\
\text { cliente. }\end{array}$ & (Lusch et al., 2007) & & & M & $\mathrm{D}$ & \\
\hline $\begin{array}{l}\mathrm{FMC}_{18} \text { - As soluções produto-serviço permitem disponibilizar serviços de } \\
\text { manutenção e reparo integrados ao produto. }\end{array}$ & $\begin{array}{l}\text { (Baines et al., 2007; } \\
\text { Goedkoop et al., 1999; Mont, } \\
\text { 2002) }\end{array}$ & & & M & $\mathrm{D}$ & \\
\hline $\begin{array}{l}\mathrm{FMC}_{19}-\text { As soluções produto-serviço permitem a utilização da capacidade } \\
\text { máxima do produto adquirido. }\end{array}$ & (Oliva \& Kallenberg, 2003) & & & M & $\mathrm{D}$ & \\
\hline $\begin{array}{l}\mathrm{FMC}_{20}-\text { As soluções produto-serviço permitem a redução dos impactos } \\
\text { ambientais devido à mudança de propriedade do bem - muitas vezes o cliente } \\
\text { não tem o conhecimento necessário para reutilizar peças ou descartar o produto. }\end{array}$ & $\begin{array}{l}\text { (Manzini \& Vezzoli, 2003; } \\
\text { Manzini et al., 2001; } \\
\text { Meijkamp, 2000) }\end{array}$ & & & M & $\mathrm{D}$ & \\
\hline
\end{tabular}

